\title{
A unique measles B3 cluster in the United Kingdom and the Netherlands linked to air travel and transit at a large international airport, February to April 2014
}

L Nic Lochlainn ${ }^{12}$, S Mandal ${ }^{3}$, R de Sousa ${ }^{14}$, K Paranthaman ${ }^{5}$, R van Binnendijk ${ }^{1}$, M Ramsay ${ }^{3}$, S Hahné ${ }^{1}$, KE Brown ${ }^{6}$

1. National Institute for Public Health and the Environment, Centre for Infectious Disease Control, Bilthoven, the Netherlands

2. European Programme for Intervention Epidemiology Training (EPIET), European Centre for Disease Prevention and Control, Stockholm, Sweden

3. Centre for Infectious Disease Surveillance and Control, Public Health England, London, United Kingdom

4. European Programme for Public Health Microbiology Training (EUPHEM), European Centre for Disease Prevention and Control, Stockholm, Sweden

5. Public Health England South East, Ashford, Kent, United Kingdom

6. Virus Reference Department, Public Health England, London, United Kingdom

Correspondence: Laura Nic Lochlainn (laura.nic.lochlainn@rivm.nl)

Citation style for this article:

Nic Lochlainn L, Mandal S, de Sousa R, Paranthaman K, van Binnendijk R, Ramsay M, Hahné S, Brown KE. A unique measles B3 cluster in the United Kingdom and the Netherlands linked to air travel and transit at a large international airport, February to April 2014. Euro Surveill. 2016;21(13):pii=30177. DOI: http://dx.doi. org/10.2807/1560-7917.ES.2016.21.13.30177

Article submitted on 30 March 2015 / accepted on 28 September 2015 / published on 31 Macrh 2016

This report describes a joint measles outbreak investigation between public health officials in the United Kingdom (UK) and the Netherlands following detection of a measles cluster with a unique measles virus strain. From 1 February to 30 April 2014, 33 measles cases with a unique measles virus strain of genotype B3 were detected in the UK and the Netherlands, of which nine secondary cases were epidemiologically linked to an infectious measles case travelling from the Philippines. Through a combination of epidemiological investigation and sequence analysis, we found that measles transmission occurred in flight, airport and household settings. The secondary measles cases included airport workers, passengers in transit at the same airport or travelling on the same flight as the infectious case and also household contacts. This investigation highlighted the particular importance of measles genotyping in identifying transmission networks and the need to improve vaccination, public health follow-up and management of travellers and airport staff exposed to measles.

\section{Introduction}

Measles is a highly contagious, acute viral illness with potential for severe complications, including pneumonia, encephalitis and death. The infectious period for measles is from four days before until four days after rash onset [1]. International travel by susceptible persons to measles-endemic areas can lead to imported sporadic cases in countries that have achieved or are close to achieving measles elimination [2,3]. Many of these sporadic cases result from measles transmission in flight or at airports [3-7]. Risk of further transmission following an importation then depends on the level of immunity in the exposed population and the responsiveness of public health agencies once a case is identified.

In 2014, 48 laboratory-confirmed measles importations were reported in the United Kingdom (UK) compared with 50 in 2013 and 27 in 2012. In the Netherlands in 2014, nine laboratory-confirmed measles importations were reported, compared with 31 in 2013 and eight in 2012. Vaccination coverage for two doses of the measles-mumps-rubella (MMR) vaccine is high in both the UK (88.3\%) [8] and the Netherlands (92.4\%) [9]. Their respective national immunisation programmes offers two doses of the MMR vaccine at 14 months and nine years in the Netherlands [10] and between 12 and 13 months and then between three years four months and five years in England [11]. Two doses of the MMR vaccine are $99 \%$ effective at preventing measles [1].

Heathrow Airport in London in the UK and Amsterdam Airport Schiphol in the Netherlands are the first and fourth busiest airports in Europe, handling ca 72.3 million and 52.6 million passengers respectively in 2013 $[12,13]$. As a consequence, these large airports present opportunities for measles importation and transmission, posing additional challenges for measles elimination in Europe [14].

In the event of an infectious measles case travelling on a flight, European risk assessment guidelines for infectious diseases transmitted on aircraft (RAGIDA), published by the European Centre for Disease Prevention and Control (ECDC), recommend that contact tracing should prioritise children aged below 2 years 


\section{FIGURE 1}

Epidemic curve of secondary measles cases

epidemiologically linked with the index case, week 5 to week 8 2014, United Kingdom and the Netherlands $(n=9)$

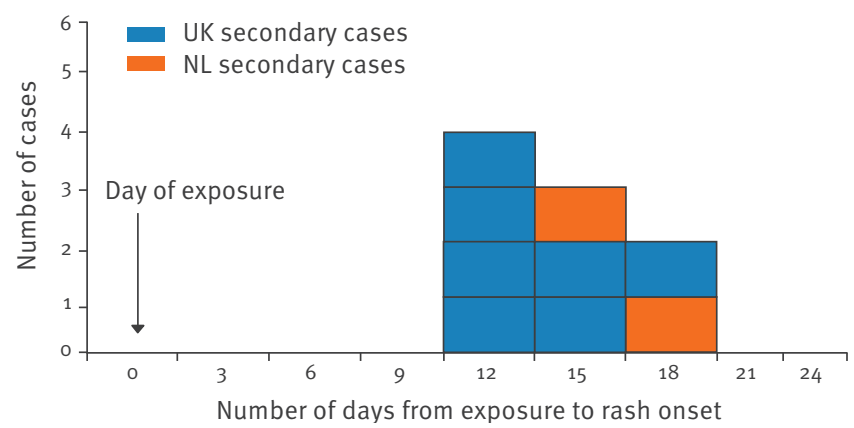

NL: the Netherlands; UK: United Kingdom.

and passengers seated in the same row as the index case. Contact tracing should then proceed row by row in either direction away from the index case, in an effort to identify vulnerable susceptible contacts on the entire flight. Timeliness is crucial in these situations, as post-exposure prophylaxis (PEP) with either vaccine or immunoglobulin needs to be administered within a few days of exposure [15]. In the UK and the Netherlands, the policy for PEP is similar to the ECDC RAGIDA guidelines [10,11].

A cluster of measles cases with onset dates from 1 February to 30 April 2014 occurred in the UK and the Netherlands and was linked to an index case that travelled from the Philippines to London, via Amsterdam Airport Schiphol, in January 2014. At this time, a large measles outbreak was ongoing in the Philippines. Although the measles cluster was only recognised when genotype information on the third UK case became available, we present the key epidemiological features and lessons learnt from the investigation and management of this cluster.

\section{Methods}

\section{Case definition}

Measles is a notifiable disease in both the UK and the Netherlands. In the UK, a suspected case of measles includes any person in whom a clinician suspects measles infection, or any person with a clinically compatible rash and fever illness [16]. In the Netherlands, the European Union (EU) measles case definition is used [17]. In all cases, samples are requested from suspect cases (oral fluid samples for detection of measles IgM and/or viral RNA in the UK; oral fluids or nasopharyngeal aspirate specimens for IgM serology and/ or detection of viral RNA in the Netherlands) to confirm the diagnosis. In this investigation, the outbreak case definition included laboratory-confirmed cases of measles notified between 1 February and 1 June 2014 with the measles virus MVs/Tonbridge.GBR/5.14 [B3] (i.e. an identical 450 nucleotide (nt) sequence) or laboratory-confirmed measles cases without genotyping but with a clear epidemiological link to cases with the measles virus MVs/Tonbridge.GBR/5.14 [B3].

\section{Laboratory investigation}

Serum or oral fluid samples were tested by commercial serological assay for measles IgM and IgG using standard methods. PCR testing and genotyping of oral fluid and or nasopharyngeal aspirates were conducted by the Virus Reference Department (VRD) at Public Health England (PHE) and by the Centre for Infectious Disease Research, Diagnostics and Screening at the Dutch National Institute for Public Health and the Environment (RIVM). Genotyping and strain identification is attempted on all confirmed measles cases. Measles genotyping involves amplification of the 450 nt fragment of the measles nucleocapsid (N) gene. Classification of genotypes is based on nucleic acid sequencing of the PCR products [18]. Measles sequences were entered and compared against other measles sequences in the World Health Organization (WHO) measles nucleotide surveillance database (MeaNS, http://www.who-measles.org), hosted by the VRD at PHE [19].

\section{Public health investigation and response}

PHE is responsible for the investigation and public health management of measles cases and contacts in England. PHE interviewed the index case immediately after notification and PEP was offered to susceptible household contacts of the case. As the index case was infectious during air travel, PHE contacted the airline for passenger contact tracing. The airline initially declined to provide the passenger and crew member list to PHE but agreed to send a letter to passengers and crew members on the flight between Amsterdam Airport Schiphol and Heathrow Airport. The letter notified them about the potential measles exposure and recommended that they contact $\mathrm{PHE}$ or their local health service if they were pregnant, had a weakened immune system, travelled with an infant less than 6 months old, or had developed symptoms compatible with measles. PHE also notified the Dutch International Health Regulation Focal Point (IHRFP) about possible exposures during the transit of the index case at Amsterdam Airport Schiphol.

The RIVM laboratory shared genotype and epidemiological information with the WHO MeaNS network about two geographically separate clusters of the outbreak strain that were identified in March 2014. RIVM alerted Municipal Health Services in regions of the Netherlands with measles cases to conduct enhanced surveillance. Subsequent cases were captured, confirmed and sequenced.

Following the identification of multiple unlinked cases with the measles virus MVs/Tonbridge.GBR/5.14 in the UK and the Netherlands, epidemiological links between UK and Dutch cases were further investigated. All possible related cases in both the UK and the Netherlands 


\section{FIGURE 2}

Possible point of exposure and chain of transmission among measles cases in the United Kingdom and the Netherlands, week 5 to week 82014

\section{Possible points of exposure}
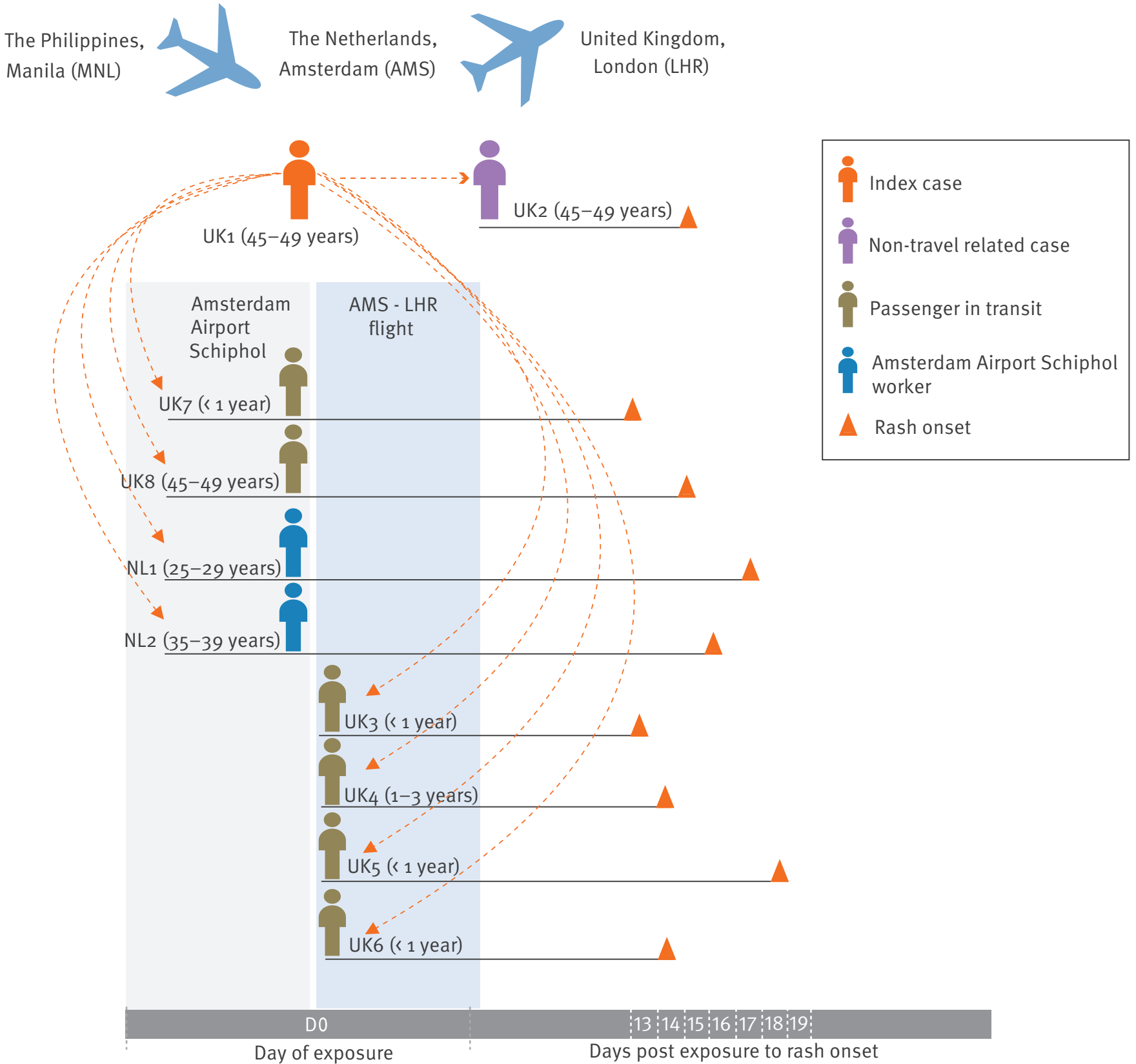

AMS: Amsterdam Airport Schiphol; LHR: Heathrow Airport; MNL: Manila Ninoy Aquino International Airport; NL: the Netherlands; UK: United Kingdom.

with the measles virus MVs/Tonbridge.GBR/5.14 were interviewed to look for common links.

\section{Results}

\section{Index case}

The index case in this cluster (UK1) was an unvaccinated adult aged 45-49 years, born in the Philippines, but currently resident in the UK. Between December 2013 and January 2014, UK1 spent two consecutive months visiting family and friends in Manila, the Philippines. While in Manila, UK1 became unwell and developed a rash in week 5 2014, the day before returning to the UK. UK1 sought medical attention in Manila, but measles was not suspected. UK1 departed Manila for Heathrow Airport the following day, transiting via Taiwan Taoyuan International Airport and Amsterdam Airport Schiphol, before arriving in the UK on the second day after rash 
Aircraft seating plan showing the index case and secondary cases on the flight from Amsterdam Airport Schiphol to Heathrow Airport (D0), week 52014

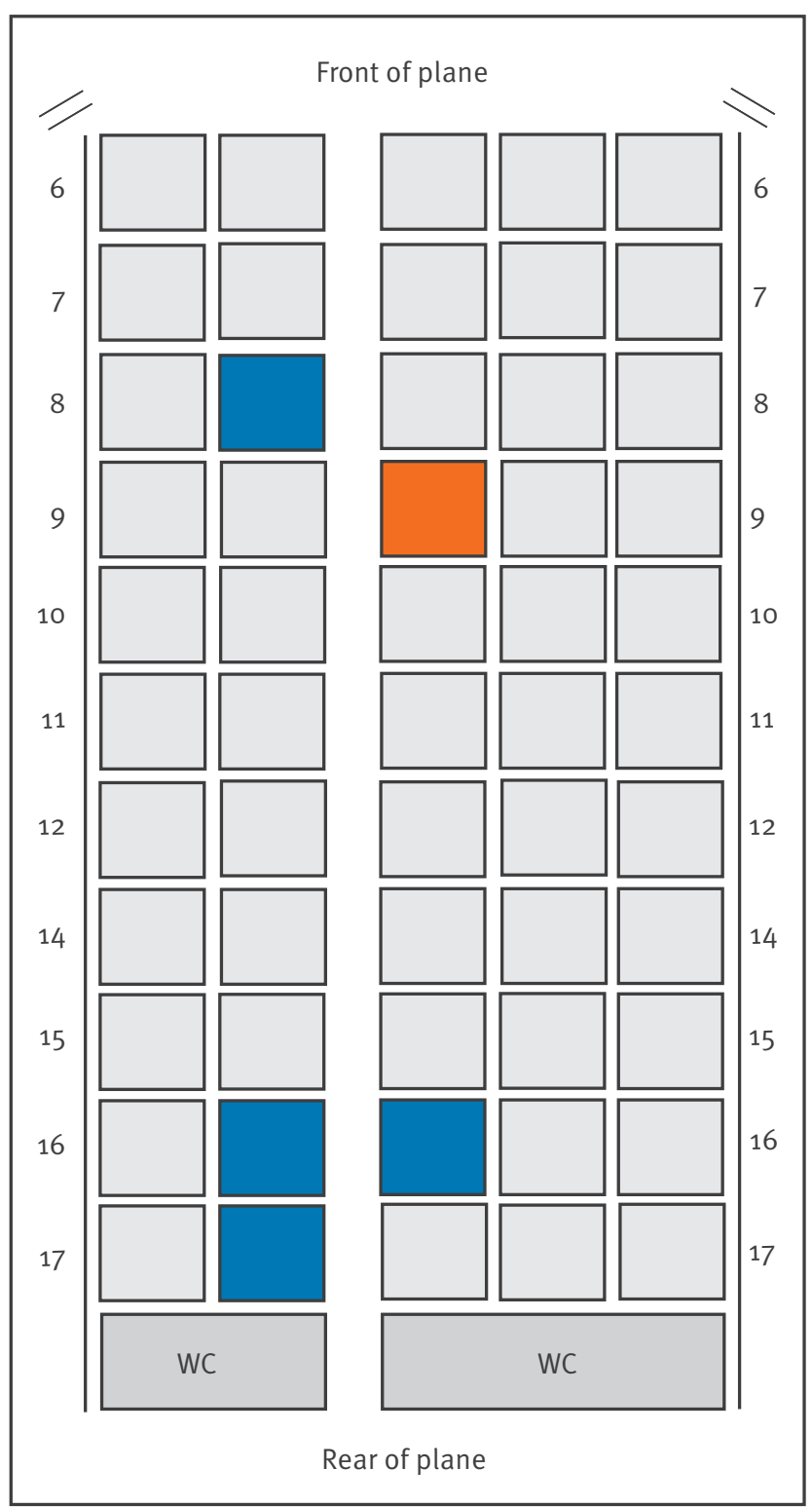

Index case Secondary case

onset. The index case spent approximately five hours at Amsterdam Airport Schiphol during transit. Due to deterioration of symptoms, UK1 attended a local hospital the day after arrival in the UK (day 3 after rash onset), where measles was clinically suspected.

\section{Laboratory results}

The diagnosis of UK1 was confirmed by serology (IgM) and detection of the virus by PCR two days after hospital attendance in week 6 2015. Sequencing results showed that UK1 had been infected with a unique measles virus strain of genotype $\mathrm{B}_{3}, \mathrm{MV}$ / /Tonbridge. GBR/5.14, (GenBank KJ650198). The sequence differed by two nucleotides from the Harare B3 sequence (Mvi/
Harare.ZWE/38.09), which by February 2014 had been associated with measles outbreaks in many countries, including the Philippines [20]. On 6 February 2014, the sequence was submitted to the WHO MeaNS database. At that time, there were no identical sequences available in either GenBank or MeaNS. With the identification of other cases with the same $450 \mathrm{nt}$ sequence, this sequence was assigned as a new measles strain type, MVs/Tonbridge.GBR/5.14, (referred to in this report as the outbreak strain).

\section{Overview of contacts}

Following identification of UK1, a further 17 cases in the UK that met the outbreak case definition were identified between week 7 and week 12 2014. Of these 17 UK cases, 16 had the outbreak strain, and one case was not sequenced but had clear epidemiological links to the index case. Seven cases with the outbreak strain in the UK could be epidemiologically linked to UK1 (Figure 1).

Six of these UK cases (UK3-UK8) were found to have transited through or travelled from Amsterdam Airport Schiphol on the same date or flight as UK1, while one case (UK2) was a household contact of the index case (Figure 2). The remaining 10 UK cases with the outbreak strain identified through surveillance activities were investigated, but could not be epidemiologically or directly linked to UK1.

In the Netherlands, 15 cases met the outbreak case definition and were identified between week 7 and week 14 2014. Two secondary cases (NL1 and NL2) could be epidemiologically linked to UK1 (Figure 1) and worked at Amsterdam Airport Schiphol (Figure 2). Four measles cases with the outbreak strain lived in the same community as NL2, near Amsterdam Airport Schiphol. The remaining nine cases with the outbreak strain occurred in The Hague, and no formal epidemiological link with UK1 was established. An overview of cases linked to $\mathrm{UK}_{1}$, of whom six were male and three were female, is shown in Table 1.

Secondary and tertiary measles cases with the outbreak strain in the United Kingdom UK2 was a household contact of UK1 during their infectious period in the UK. UK2 was an unvaccinated adult aged 45-49 years, with no history of recent travel outside of the UK. UK2 received a post-exposure MMR vaccination within 24 hours following contact with UK1, but developed measles rash 15 days post exposure.

UK3 was an unvaccinated infant aged $<1$ year old returning from a country in southern Africa to the UK via Amsterdam Airport Schiphol. UK3 was on the same flight as UK1 from Amsterdam to London and was seated on a parent's lap. UK3 developed measles rash 13 days post exposure.

UK4 was an unvaccinated child aged $1-3$ years returning from a country in southern Africa to the UK via 
Summary of measles cases in the United Kingdom and the Netherlands linked to air travel and transit at Amsterdam Airport Schiphol, week 5 to week $82014(\mathrm{n}=10)$

\begin{tabular}{|c|c|c|c|c|}
\hline Case number & Age (given as range) & Number of days post-exposure to rash onset & Measles vaccination status & Transmission setting \\
\hline $\begin{array}{l}\text { UK1 (index } \\
\text { case) }\end{array}$ & $45-49$ years & Do & o doses & Unknown \\
\hline UK2 & $45-49$ years & 15 & 1 post-exposure MMR & Household contact \\
\hline $\mathrm{UK}_{3}$ & «1 year & 13 & o doses & Airport/same flight \\
\hline UK4 ${ }^{\mathrm{a}}$ & $1-3$ years & 14 & o doses & Airport/same flight \\
\hline $\mathrm{UK}_{5}$ & «1 year & 19 & o doses & Airport/same flight \\
\hline UK6 & «1 year & 14 & o doses & Airport/same flight \\
\hline $\mathrm{UK}_{7}$ & «1 year & 13 & o doses & Airport \\
\hline UK8 & $45-49$ years & 15 & o doses & Airport \\
\hline NL1 & $25-29$ years & 18 & $\begin{array}{c}1 \text { monovalent measles vaccine } \\
\text { and } 2 \text { MMR doses }\end{array}$ & Airport \\
\hline NL2 & $35-39$ years & 16 & 1 MMR dose & Airport \\
\hline
\end{tabular}

MMR: measles-mumps-rubella vaccine.

a Not genotyped, rash onset date consistent with acquisition of infection on the flight or at Amsterdam Airport Schiphol.

Amsterdam Airport Schiphol. While not genotyped, UK4 had rash onset 14 days post exposure, which is consistent with acquisition of infection on the flight or at Amsterdam Airport Schiphol, rather than in the household setting.

UK5 was an unvaccinated infant $<1$ year old and a sibling of UK4. UK5 was also on the same flight as UK1 from Amsterdam to London, and was seated in a bassinet. UK5 developed measles rash 19 days post exposure.

UK6 was an unvaccinated infant aged $<1$ year old returning from a country in southern Africa. UK6 was on the same flight as UK1 from Amsterdam to London, and seated on a parent's lap. UK6 developed measles rash 14 days post exposure.

Of the four UK secondary cases (UK3, UK4, UK5, UK6) who were on the same flight as UK1, only one case was seated within one row of UK1, while the remaining three cases were seated near the rear of the plane, six to seven rows from UK1 (Figure 3).

The remaining two secondary cases, an unvaccinated infant aged $<1$ year old (UK 7 ) and an unvaccinated adult aged 45-49 years (UK8) were not on the same flight as UK1. However, both cases were in transit at Amsterdam Airport Schiphol on the same day as UK1. UK7 was en route to the Caribbean and had flown with the same airline as UK1, and used the same gate area. UK7 developed a measles rash 13 days post exposure. UK8 was flying from Amsterdam Airport Schiphol to Gatwick Airport in the UK but had flown with a different airline from a different gate. UK8 developed measles rash 15 days post exposure.
The ten UK cases, who were infected with the outbreak strain but were not epidemiologically linked to the index case, were in the age range of $<1$ year and 49 years. Nine cases were not known to have travelled abroad, with five cases clustered in Newcastle and two cases clustered in a different area of the country. One measles case had been on a cruise ship in Italy in late February 2014, which reported a measles outbreak with the same outbreak strain [21].

Secondary and tertiary measles cases with the outbreak strain in the Netherlands

In March 2014, RIVM identified measles cases with the same outbreak strain among two Amsterdam Airport Schiphol workers (Table 1). The outbreak strain was first identified in the Netherlands in an Amsterdam Airport Schiphol worker (NL1) aged 25-29 years. NL1 had received a single dose of monovalent measles vaccine and two doses of MMR vaccine in the past. NL1 had measles rash onset 18 days post exposure. NL1 worked at the airport on the morning that UK1 was in transit.

The second outbreak strain case was an Amsterdam Airport Schiphol worker aged 35-39 years (NL2) who had received one dose of MMR vaccine in the past. NL2 had measles rash onset 16 days post exposure and was hospitalised for four days due to general malaise and rash. NL2 was the only case in this cluster to require hospitalisation.

Between week 11 and week 14 2014, an additional four measles cases with the outbreak strain were detected in the community where NL2 lived, which was close to the airport. All four cases were unvaccinated and in the age range of 15 to 44 years. 
The remaining nine Dutch cases with the outbreak strain but not epidemiologically linked to the index case were aged between $<1$ year and 44 years. These cases were involved in two separate cluster events in The Hague. Five cases with the outbreak strain were involved in a kindergarten measles cluster. We were unable obtain information relating to recent travel. However, four of the five cases reported that the source of infection was at the kindergarten. Four cases were involved in a hospital measles cluster. Two of these four cases had a history of recent travel, but travelled after onset of measles symptoms.

\section{Discussion}

This report describes measles transmission in multiple settings in the UK and the Netherlands linked to an infectious traveller returning from the Philippines. Secondary transmission occurred firstly in passengers in transit and workers at Amsterdam Airport Schiphol; secondly, to passengers before or during a flight from the Netherlands to the UK and thirdly, in the household setting of the index case in the UK. One secondary case required hospitalisation due to general malaise and rash. Tertiary transmission occurred in the Netherlands in a community close to the airport. Additional cases with the outbreak strain were also identified in both the UK and the Netherlands, but could not be epidemiologically linked. We did not follow up other passengers potentially exposed on the Manila to Taipei and Taipei to Amsterdam flights, as there was no efficient method known to contact potentially exposed passengers. Therefore, there may have been additional or unreported cases linked to this cluster in the UK and the Netherlands.

The index case in this cluster developed measles in the Philippines, having spent two months there before departure to the UK, and where a large measles outbreak was ongoing $[20,22]$. Historically, the measles genotypes in clade $B$ have been associated with subSaharan Africa $[19,23]$, but genotype $B 3$ is now widely distributed throughout the world, and associated with many outbreaks [24-26]. However, the outbreak strain we describe in this cluster had not been previously reported. The ability to identify the outbreak strain in the UK and subsequently in the Netherlands confirms the utility of having timely submission of sequences to the WHO MeaNS database. Exchange of information regarding epidemiological risk and exposures between the public health authorities in the UK and the Netherlands made it possible to link the cases in the Netherlands to the index case.

In a separate event in late February 2014, a measles outbreak on a cruise ship in Italy reported cases with the same strain [21]. At the time of reporting of this cruise ship outbreak, the only reference for this unique B3 sequence type was that of UK1. No epidemiological link was identified between UK1 and the cruise ship outbreak [27]. A UK case with the outbreak strain who had been on the cruise ship was later identified in March 2014. Three measles cases on the cruise ship outbreak were from the Philippines [21], which suggests the circulation of the novel B3 strain in the Philippines in early 2014 .

Four UK cases in this cluster who were at the same airport or on the same flight as the index case were aged under 12 months and were not yet eligible for routine MMR vaccination in England [11]. Young unvaccinated children are at increased risk of measles and its complications [1]. Given the risk of measles while travelling to countries with endemic or epidemic transmission, current national recommendations in both the UK and the Netherlands advise that children aged over 6 months of age should be considered for an early dose of MMR vaccine before travel $[10,11]$. The data from this report suggests that infants travelling through major international hubs are at risk of measles infection and an early MMR vaccination should be considered by their parents or guardians.

Four adult cases (UK1, UK2, UK8, and NL2) were unvaccinated or had received only a single MMR vaccine. This represents a susceptible group of adults who were either not exposed to measles during childhood or were not fully vaccinated in routine MMR vaccination programmes. Measles is still endemic in many countries and measles outbreaks are occurring on a global scale [28]. It is therefore important that travellers obtain appropriate advice when travelling, to ensure that they are fully protected against measles and other vaccine-preventable diseases.

In this cluster, two measles cases were airport workers at Amsterdam Airport Schiphol. In a separate measles cluster in the Netherlands in January and February 2014, two other airport workers at Amsterdam Airport Schiphol, who were both unvaccinated and required hopsitalisation for measles complications, were found to have a genotype $\mathrm{B}_{3}$ strain identical to the $\mathrm{MVi}$ / Harare.ZWE/38.09 strain. Additional cases with the $\mathrm{MVi} /$ Harare.ZWE/38.09 strain were detected in their communities, indicating possible tertiary transmission. In 2013 and 2014, this strain was detected in cases imported from the Philippines into Canada, Japan and the United States, and in 10 cases in the UK [24-26]. Staff at large international airports risk possible exposure to infectious diseases from travellers. Therefore, in order to prevent the spread of measles, occupational health departments at airports could consider checking the vaccination status of airport workers to ensure they are fully vaccinated.

The recommendation by RAGIDA to prioritise contact tracing among those under 2 years of age is well-justified [15]. In this report, four of the secondary cases who contracted measles met these criteria for prioritisation. However, the RAGIDA recommendation to prioritise contact tracing of the remaining passengers by proximity to the index case may not be sufficiently sensitive for a highly communicable infection such as 
measles. Firstly, measles exposure may have occurred in flight, while waiting at the gate or during the boarding process. Secondly, three out of four cases in the cluster were seated six to seven rows from the index case. Furthermore, when PHE contacted the airline to obtain passenger information, the airline was initially unwilling to release passenger details, despite assurances and regulations [29]. This hampered the targeted contact tracing as part of the public health investigation and response. Sending an email or text message to all potential exposed crew and passengers, rather than row by row as recommended in the RAGIDA guidelines, may be more feasible. This method, adopted by PHE when they are able to obtain the information in a timely manner from an airline, serves not only to rapidly identify vulnerable groups but also to remind those who are unvaccinated to receive their MMR vaccine. Early identification of potentially exposed cases could have limited further community spread. There is therefore a need for an efficient method to obtain passenger information and contact details that can be globally adopted by airline companies and enforced by their regulatory authorities. Additionally, by rapidly contacting potentially exposed cases, public health authorities could provide appropriate health messages or interventions to prevent tertiary spread in the wider community.

\section{Conclusion}

This report highlights the importance of sequence databases in epidemiological investigations and shows how a global effort to update circulating measles strains could assist in identifying the geographical origin of importations. This is particularly important as many countries progress towards measles elimination and therefore need to demonstrate absence of sustained indigenous transmission. Identification of clusters, combined with rapid public health responses, can limit further spread. However, public health response is reliant on rapidly identifying exposed cases. Therefore, improvements in vaccination of airport workers, in vaccine recommendations to those travelling and airline contact tracing should be made, to ensure exposed contacts are rapidly identified.

\section{Acknowledgements}

The authors would like to acknowledge those who work in the health protection teams, municipal health services, laboratories and as clinicians in the UK and the Netherlands for reporting and investigating cases. The authors would also like to gratefully acknowledge the following people for their support with this investigation: Anne de Vries and Nicole Leersen of the Kennemerland Municipal Health Service; Jane Pattipeilohy of the Utrecht Region Municipal Health Service; Daphne Gijselaar and Jeroen Cremer of the Centre for Infectious Disease Research, Diagnostics and Screening, RIVM; Antoaneta Bukasa of the Centre for Disease Surveillance and Control, PHE, and Kostas Danis of the European Programme for Intervention Epidemiology Training (EPIET) for reviewing and commenting on the manuscript.
Conflict of interest

None.

Authors' contributions

$\mathrm{KEB}, \mathrm{RB}$ and $\mathrm{SH}$ coordinated the investigation. KP interviewed the index case in the UK. SM collected and interpreted case data in the UK. LN and RdS collected and interpreted case data in the Netherlands. KEB and RB coordinated genotyping and interpretation of the measles results in the UK and the Netherlands, respectively. Each author contributed to the content of the report and participated in drafting and revising the manuscript.

\section{References}

1. Strebel PM, Papania MJ, Fiebelkorn AP, Halsey NA. Measles vaccine. In: Plotkin S, Orenstein W, Offit P, editors. Vaccines. 6th ed. Philadelphia, PA: Saunders; 2012.

2. Chen TH, Nilles EJ, Souarés Y. Crossing borders: one world, global health.Clin Infect Dis. 2014;58(7):v-vi. DOI: 10.1093/cid/ ciu101 PMID: 24627562

3. Edelson PI. Patterns of measles transmission among airplane travelers.Travel Med Infect Dis. 2012;10(5-6):230-5. DOI: 10.1016/j.tmaid.2012.10.003 PMID: 23127863

4. Coleman KP, Markey PG. Measles transmission in immunized and partially immunized air travellers. Epidemiol Infect. 2010;138(7):1012-5. DOI: 10.1017/S0950268809991129 PMID: 19878613

5. Nelson K, Marienau K, Schembri C, Redd S. Measles transmission during air travel, United States, December 1, 2008-December 31, 2011.Travel Med Infect Dis. 2013;11(2):81-9. DOI: 10.1016/j.tmaid.2013.03.007 PMID: 23562445

6. van Binnendijk RS, Hahné S, Timen A, van Kempen G, Kohl $\mathrm{RH}$, Boot $\mathrm{HJ}$, et al. Air travel as a risk factor for introduction of measles in a highly vaccinated population. Vaccine. 2008;26(46):5775-7. DOI: 10.1016/j.vaccine.2008.08.048 PMID: 18786588

7. Rota J, Lowe L, Rota P, Bellini W, Redd S, Dayan G, et al. Identical genotype $B_{3}$ sequences from measles patients in 4 countries, 2005. Emerg Infect Dis. 2006;12(11):1779-81. DOI: 10.3201/eid1211.060635 PMID: 17283637

8. Health and Social Care Information Centre. NHS Immunisation Statistics, England - 2013-14. 25 Sep 2014; Available from: http://www.hscic.gov.uk/catalogue/PUB14949

9. van Lier EA, Oomen PJ, Giesbers H, Conyn-van Spaendonck MAE, Drijfhout IH, Zonnenberg-Hoff IF, et al. Vaccinatiegraad Rijksvaccinatieprogramma Nederland. [Vaccination Coverage Dutch National Immunisation Programme]. 2014. Dutch. Available from: http://www.rivm.nl/bibliotheek/ rapporten/150202003.pdf

10. Landelijke coördinatie infectieziektebestrijding, Rijksinstituut voor Volksgezondheid en Milieu (RIVM). LCI-richtlijn mazelen. [Measles guidelines]. 2011; Dutch. Available from: http:// www.rivm.nl/Documenten en publicaties/Professioneel Praktisch/Richtlijnen/Infectieziekten/LCI_richtlijnen/ LCl_richtlijn_Mazelen_morbilli

11. Public Health England. UK immunisation schedule: the green book, chapter 11. 30 April 2014. p. 80. Available from: https://www.gov.uk/government/publications/ immunisation-schedule-the-green-book-chapter-11

12. Schiphol Group. Facts \& Figures 2013. 2013; Available from: http://www.schiphol.nl/SchipholGroup/Company1/Statistics/ FactsFigures.htm

13. Civil Aviation Authority. Table 8: Air passengers by type and nationality of operator 2013. In: UK Airports (including Channel Islands \& Isle of Man) - Movement, Passenger and Cargo Statistics 2013; Available from: http://www.caa.co.uk/ Data-and-analysis/UK-aviation-market/Airports/Datasets/ UK-Airport-data/Airport-data-1990-onwards/

14. Steffens I, Martin R, Lopalco P. Spotlight on measles 2010: measles elimination in Europe - a new commitment to meet the goal by 2015. Euro Surveill. 2010;15(50):19749.PMID: 21172176

15. European Centre for Disease Prevention and Control (ECDC). Risk assessment guidelines for diseases transmitted on aircraft. 2nd ed. Stockholm: ECDC; 2010 . Available from: http://ecdc.europa.eu/en/healthtopics/ragida/Pages/default. aspx

16. Public Health England (PHE). National Measles Guidelines. Version 1.2. 28 Oct 2010. Available from: https://www.gov. 
uk/government/uploads/system/uploads/attachment_data/ file/322932/National_Measles_Guidelines.pdfhttp://

17. European Centre for Disease Prevention and Control (ECDC). Measles. (Accessed 16 Oct 2014). Available from: http://ecdc. europa.eu/en/activities/surveillance/euvac/case_definition/ pages/measles.aspxhttp://

18. World Health Organisation (WHO),. Global distribution of measles and rubella genotypes--update.Wkly Epidemiol Rec. 2006;81(51/52):474-9.PMID: 17175602

19. Rota PA, Brown K, Mankertz A, Santibanez S, Shulga S, Muller $\mathrm{CP}$, et al. Global distribution of measles genotypes and measles molecular epidemiology. J Infect Dis. 2011;204(Suppl 1):S514-23. DOI: 10.1093/infdis/jir118 PMID: 21666208

20. Regional Office for the Western Pacific (WPRO) World Health Organization (WHO). Measles Rubella Bulletin. Volume 8, Issue 2. February 2014. Available from: http://iris.wpro. who.int/bitstream/handle/10665.1/11076/Measles-Rubella Bulletin_2014_Vol_08_No_02.pdf;jsessionid $=55$ ABEE2Fo8 15 C 7 $064 \mathrm{AB} 90193 \mathrm{~B}_{167 \mathrm{D}_{1} \mathrm{D} 2}$ ? sequence $=1$

21. Central task force for measles outbreak,Lanini $S$,

Capobianchi MR, Puro V, Filia A, Del Manso M, Karki T, et al. . Measles outbreak on a cruise ship in the western Mediterranean, February 2014, preliminary report.Euro Surveill. 2014;19(10):20735. DOI: 10.2807/1560-7917. ES2014.19.10.20735 PMID: 24650863

22. Regional Office for the Western Pacific (WPRO) World Health Organization (WHO). Measles Rubella Bulletin. Volume 8, Issue 4. April 2014. Available from: http://iris.wpro.who. int/bitstream/handle/10665.1/11074/Measles-Rubella_ Bulletin_2014_Vol_08_No_04.pdf?sequence=1

23. Riddell MA, Rota JS, Rota PA. Review of the temporal and geographical distribution of measles virus genotypes in the prevaccine and postvaccine eras.Virol J. 2005;2(1):87. DOI: 10.1186/1743-422X-2-87 PMID: 16303052

24. BC Centre for Disease Control (BCCDC). Measles Epidemiological Summary British Columbia: January 1 to July 19, 2014; Epidemiologic weeks 1 to 29. 2014; Available from: http://www.bccdc.ca/NR/rdonlyres/B9B9C05C-4D80-4DD2B2C2-B64CA41068C8/o/MeaslesBCupdatetoweek292014final. pdf

25. Takahashi T, Arima Y, Kinoshita H, Kanou K, Saitoh T, Sunagawa T, et al. Ongoing increase in measles cases following importations, Japan, March 2014: times of challenge and opportunity. Western Pac Surveill Response J. 2014;5(2):31-3. DOI: 10.5365/wpsar.2014-5.2.001 PMID: 25077035

26. Centers for Disease Control and Prevention (CDC),Zipprich J, Hacker JK, Murray EL, Xia D, Harriman K, Glaser C. Notes from the field: measles - California, January 1-April 18, 2014.MMWR Morb Mortal Wkly Rep. 2014;63(16):362-3.PMID: 24759659

27. Mandal S, Ramsay M, Brown K. Measles on a cruise ship: links with the outbreak in the Philippines.Euro Surveill. 2014;19(15):20774. DOI: 10.2807/1560-7917. ES2014.19.15.20774 PMID: 24762665

28. Centers for Disease Control and Prevention (CDC),Perry RT, Gacic-Dobo M, Dabbagh A, Mulders MN, Strebel PM, OkwoBele JM, et al. . Global control and regional elimination of measles, 2000-2012. MMWR Morb Mortal Wkly Rep. 2014;63(5):103-7.PMID: 24500289

29. World Health Organisation (WHO). International

Health Regulations (2005). Second edition. Geneva: WHO; 2008. Available from: http://www.who.int/ihr/ publications/9789241596664/en/

\section{License and copyright}

This is an open-access article distributed under the terms of the Creative Commons Attribution (CC BY 4.0) Licence. You may share and adapt the material, but must give appropriate credit to the source, provide a link to the licence, and indicate if changes were made.

This article is copyright of the authors, 2016. 